\title{
Reaksi Silang Serum Unggas terhadap Virus Avian Influenza H5N1 Clade 2.1.3 dan 2.3.2 dengan Uji Hemaglutinasi Inhibisi
}

\section{(Cross Reaction of Poultry Serum Against Avian Influenza Virus H5N1 Clade 2.1.3 and 2.3.2 by Hemaglutination Inhibition Test)}

\author{
Indriani R, Dharmayanti NLPI, Martindah E \\ Balai Besar Penelitian Veteriner, Jl. RE Martadinata No. 30, Bogor 16114 \\ risain52@yahoo.com
}

\begin{abstract}
Avian Influenza virus H5N1 has existed in Indonesia and was detected as a clade 2.1.3 in 2003, and then in 2012 was detected H5N1 clade 2.3.2. Clade 2.1.3 and 2.3.2 has a low level of homology at genetic of nucleotide or amino acid. This study aims to determine cross reaction between Avian Influenza (AI) antigen (virus) H5N1 clade 2.1.3 and 2.3.2 in poultry (chickens and ducks) serum, which were vaccinated with inactivated $\mathrm{AI}$ H5N1 vaccine clade 2.1.3 against AI $\mathrm{H} 5 \mathrm{~N} 1$ antigen clade 2.3.2 and vaccinated inactivated AI H5N1 vaccine clade 2.3.2 against H5N1 antigen clade 2.1.3. Serum was obtained from chickens and ducks post-vaccination and unvaccinated (control) in laboratory conditions, and from ducks post-vaccination AI H5N1 in field condition. HI test is run by using AI H5N1 antigen clade 2.1.3 and clade 2.3.2. Results were analysed by the geometric means and anova test. HI test results show cross reaction with low antibody titers between chicken and duck serum post-vaccination of $\mathrm{H} 5 \mathrm{~N} 1$ clade 2.3 .2 with clade 2.1.3 antigen, whereas serum of chicken and duck post-vaccination of AI H5N1 clade 2.1.3 against clade 2.3.2 antigen shows cross reactions with high antibody titers. Conclusion of this study, postvaccination serum of AI $\mathrm{H} 5 \mathrm{~N} 1$ clade 2.1.3 provide cross-reaction better than the post vaccination serum of H5N1 clade 2.3.2.
\end{abstract}

Key Words: Serum, Chicken, Duck, AI H5N1, Clade 2.1.3, Clade 2.3.2

\begin{abstract}
ABSTRAK
Virus Avian Influenza (H5N1) telah ada di Indonesia dan terdeteksi sebagai clade 2.1.3 pada tahun 2003, kemudian pada tahun 2012 terdeteksi H5N1 clade 2.3.2. Clade 2.1.3 dan 2.3.2 mempunyai tingkat homologi yang rendah pada genetik nukleotida maupun asam amino. Studi ini bertujuan menentukan reaksi silang antara antigen (virus) avian influenza (AI) H5N1 clade 2.1.3 dan 2.3.2 di dalam serum unggas (ayam dan itik) yang mendapat vaksinasi vaksin inaktif AI H5N1 clade 2.1.3 terhadap antigen AI H5N1 clade 2.3.2 dan yang mendapat vaksinasi vaksin inaktif AI $\mathrm{H} 5 \mathrm{~N} 1$ clade 2.3.2 terhadap antigen $\mathrm{H} 5 \mathrm{~N} 1$ clade 2.1.3. Serum uji diperoleh dari serum ayam dan itik coba pasca vaksinasi dan kontrol (tidak divaksinasi) pada kondisi laboratorium dan serum itik lapang pasca-vaksinasi AI H5N1. Uji HI dilakukan dengan menggunakan antigen AI H5N1 clade 2.1.3 dan clade 2.3.2. Hasil dianalisis menggunakan geometric means dan uji ANOVA. Hasil uji HI menunjukkan reaksi silang baik serum ayam maupun itik pasca vaksinasi AI H5N1 clade 2.3.2 dengan antigen clade 2.1.3 terjadi dengan titer antibodi rendah, sedangkan serum ayam maupun serum itik pasca vaksinasi avian influenza $\mathrm{H} 5 \mathrm{~N} 1$ virus clade 2.1.3 menunjukkan reaksi silang dengan titer antibodi tinggi terhadap antigen clade 2.3.2. Simpulan dari studi ini, serum pascavaksinasi vaksin AI H5N1 clade 2.1.3 memberikan reaksi silang lebih baik, bila dibandingkan dengan serum pasca vaksinasi $\mathrm{AI}$ H5N1 clade 2.3.2.
\end{abstract}

Kata Kunci: Serum, Ayam, Itik, AI H5N1, Clade 2.1.3, Clade 2.3.2 


\section{PENDAHULUAN}

Virus Avian Influenza (H5N1), telah menyebar ke beberapa negara di dunia dan menyebabkan tingkat kematian yang tinggi terutama pada unggas. Virus H5N1 clade 2.1.3 pertama kali terdeteksi di Indonesia pada akhir tahun 2003 (Dharmayanti et al. 2004; Wiyono et al. 2004), yang menyebabkan banyak kematian pada ayam dan merugikan secara ekonomi. Pada bulan September-November 2012 terjadi banyak kematian itik di daerah Jawa Tengah, DI Yogyakarta dan Jawa Timur. Diketahui penyebabnya adalah virus AI H5N1 clade 2.3.2 (Wibawa et al. 2012). Para ahli berpendapat virus AI H5N1 clade 2.3.2 bukan keturunan dari virus AI H5N1 clade 2.1.3 yang sebelumnya ada di Indonesia. Hal ini berdasarkan dari tingkat homologi yang rendah (91-93\%) dengan virus-virus dari clade 2.1.3 (Wibawa et al. 2012).

Unggas (ayam dan itik) yang divaksinasi AI H5N1 dapat terhindar dari kemungkinan terinfeksi virus AI H5N1 yang ada di lapangan, baik terhadap clade 2.1.3 maupun clade 2.3.2. Vaksin memberikan respon imun protektif yang sebagian besar dihasilkan oleh hemagglutinin (HA) dan sedikit neuraminidase (NA) yang terdapat di dalam antigen vaksin. Respon imun pasca vaksinasi pada unggas dapat diukur dengan uji hemaglutinasi inhibisi (HI) melalui serum. Vaksin AI H5N1 yang beredar saat ini di pasaran adalah vaksin AI H5N1 clade 2.1.3 dan vaksin AI H5N1 clade 2.3.2. Studi untuk melihat tingkat reaksi silang dari vaksin AI H5N1 clade 2.1.3 dan vaksin AI H5N1 clade 2.3.2 pada unggas (ayam dan itik) dilakukan dan dibahas pada makalah ini.

\section{MATERI DAN METODE}

\section{Serum ayam dan itik uji}

Serum diperoleh dari kelompok ayam dan itik divaksinasi dengan vaksin AI H5N1 clade 2.1.3 dan kelompok ayam dan itik divaksinasi AI H5N1 clade 2.3.2 di laboratorium (BB Litvet) dan dari itik yang divaksinasi AI H5N1 di lapangan (peternak). Ayam specific pathogen free (SPF) umur tiga minggu dikelompokkan menjadi tiga masing-masing 20 ekor yaitu: (1) Kelompok yang divaksinasi dengan vaksin inaktif AI H5N1 clade 2.1.3; (2) Kelompok yang divaksinasi dengan vaksin inaktif AI H5N1 clade 2.3.2; dan (3) Kelompok yang tidak divaksin (sebagai kontrol). Itik lokal umur tiga minggu (maternal antibodi AI H5N1 telah mencapai 0), dibagi menjadi tiga kelompok masing-masing 20 ekor yaitu: (1) Divaksinasi dengan vaksin inaktif AI H5N1 clade 2.3.2; (2) Kelompok yang divaksinasi vaksin inaktif AI H5N1 clade 2.1.3; dan (3) Kelompok yang tidak divaksinasi (sebagai kontrol). Selanjutnya ayam dan itik umur enam minggu (tiga minggu pasca vaksinasi) dari setiap kelompok dikoleksi serum darah untuk diuji hemaglutinasi inhibisi (HI) menggunakan antigen AI H5N1 clade 2.1.3 dan AI H5N1 clade 2.3.2 guna mendeteksi antibodi pasca vaksinasi.

Serum itik sebanyak 40 sampel yang mendapat vaksinasi AI H5N1 yang tidak diketahui clade-nya diperoleh dari lapang diuji HI menggunakan antigen AI H5N1 clade 2.1.3 dan AI H5N1 clade 2.3.2.1 guna mendeteksi antibodinya.

\section{Persiapan antigen AI H5N1 clade 2.1.3 dan clade 2.3.2}

Antigen untuk uji $\mathrm{HI}$ disiapkan dari virus AI H5N1 clade 2.3.2 A/Duck/Sukoharjo/Bbvw-1428-9/2012 (BBVet-Wates-Jogja) dan virus AI H5N1 clade 2.1.3. A/Ck/Wj/PWT-Wij/2006 (BBLitvet). Masing-masing virus di perbanyak di dalam 
telur ayam SPF umur 11 hari dan di inaktifasi dengan perbandingan (1:2000) Bpropiolacton (Indriani \& Dharmayanti 2015).

\section{Uji serologi hemaglutinasi inhibisi (HI)}

Serum ayam uji di inaktif sebelum digunakan selama satu jam pada $56^{\circ} \mathrm{C}$ untuk menghilangkan inhibitor spesifik (Pedersen 2008; OIE 2012). Serum itik diabsorpsi dengan sel darah merah untuk menghapus aglutinin non-spesifik (kadang menyebabkan aglutinasi non-spesifik sel darah merah ayam) (Pedersen 2008; OIE 2012; WHO 2002) sebelum digunakan uji HI. Sebanyak $50 \mu 1$ serum dari setiap sampel serum itik ditambah $50 \mu 1$ 10\% sel darah merah ayam di dalam PBS (OIE 2012) ke dalam cawan mikro tipe V (serum dianggap sebagai pengenceran 1:2), selanjutnya diinkubasi pada $4^{\circ} \mathrm{C}$ selama 1 jam. Setelah inkubasi, campuran serum dan darah disentrifugasi pada kecepatan 800 g selama 5 menit untuk memisahkan sel darah merah. Kemudian $25 \mathrm{ml}$ dipindahkan ke dalam cawan mikro pada lubang pertama yang telah berisi $25 \mu 1$ PBS. Serum itik telah terdilusi 1:2 pada awal tes HI, oleh karena itu titer terdeteksi minimal yang diberikan oleh uji HI adalah 4 (2 $\log 2$ ) untuk serum itik, sedangkan serum ayam 2 (1 log 2). Uji HI dilakukan dengan $1 \%$ sel darah merah ayam di dalam PBS dan mengunakan 4 unit hemaglutinasi (HAU) (OIE 2012). Titer HI dinyatakan sebagai nilai timbal balik dari pengenceran tertinggi serum menyebabkan penghambatan lengkap aglutinasi dari 4 antigen HAU. Titer HI 16 (4 log 2) diklasifikasikan sebagai positif untuk antibodi flu burung, menurut pedoman OIE (2012). Prosedur uji HI mengikuti OIE (2012).

\section{Analisis}

Hasil uji HI dikalkulasi dengan geometric means titer (GMT) dan dianalisis dengan ANOVA untuk signifikansi $(\mathrm{P}<0,05)$.

\section{HASIL DAN PEMBAHASAN}

Serum ayam coba laboratorium yaitu; ayam pasca vaksinasi vaksin inaktif AI H5N1 clade 2.1.3 terhadap antigen AI H5N1 clade 2.1.3 memperlihatkan rerata titer 5,6 log 2 dengan confident interval (CI) 5,1-6, dan reaksi silang terhadap antigen AI H5N1 clade 2.3.2 memperlihatkan rerata titer 4,9 $\log 2$ dengan CI 4,3-5,3 (Gambar 1). Serum ayam pasca vaksinasi vaksin inaktif AI H5N1 clade 2.3.2 terhadap antigen AI H5N1 clade 2.3.2 memperlihatkan rerata titer antibodi 6,8 $\log 2$ dengan CI 6,2-7,4; dan reaksi silang terhadap antigen AI H5N1 clade 2.1.3 menunjukkan rerata titer antibodi 2,8 log 2 dengan CI 2,4-3,2. Sementara serum ayam SPF tidak divaksinasi memperlihatkan negatif titer antibodi baik terhadap antigen AI H5N1 clade 2.1.3 maupun clade 2.3.2 (Gambar 1). Serum ayam divaksinasi AI H5N1 clade 2.1.3 dan serum ayam divaksinasi AI H5N1 clade 2.3.2 menunjukkan adanya reaksi silang dengan antigen $\mathrm{AI}$ H5N1 clade 2.1.3 dan clade 2.3.2. Hasil uji HI menunjukkan titer serum ayam tertinggi ketika diuji dengan antigen homolog (Antigen vaksin sama dengan antigen uji HI). Titer HI reaksi silang memperlihatkan perbedaan yang signifikan $(\mathrm{P}<0,05)$ antara serum ayam divaksinasi AI H5N1 clade 2.1.3 dengan antigen uji HI clade 2.3.2 terhadap serum AI H5N1 clade 2.3.2 dengn antigen uji HI clade 2.1.3.

Serum itik coba laboratorium yaitu; itik pasca vaksinasi vaksin inaktif AI H5N1 clade 2.1.3 terhadap antigen AI H5N1 clade 2.1.3 memperlihatkan rerata titer 4,4 log 2 dengan confident interval (CI) 3,7-5,1 dan reaksi silang terhadap antigen AI H5N1 clade 2.3.2 memperlihatkan rerata titer 3,5 log 2 dengan CI 2,9-4 (Gambar 2). Serum itik pasca- 
vaksinasi vaksin inaktif $\mathrm{AI} \mathrm{H} 5 \mathrm{~N} 1$ clade 2.3.2 terhadap antigen $\mathrm{AI} \mathrm{H} 5 \mathrm{~N} 1$ clade 2.3.2 memperlihatkan rerata titer antibodi 4,7 log 2 dengan CI 4-5, dan reaksi silang terhadap antigen AI H5N1 clade 2.1.3 tidak memperlihatkan adanya titer antibodi (0 $\log 2)$. Sedangkan serum itik divaksinasi memperlihatkan negatif titer antibodi baik terhadap antigen AI H5N1 clade 2.1.3 maupun clade 2.3.2 (Gambar 2). Serum itik tidak divaksinasi memperlihatkan negatif titer antibodi baik terhadap antigen AI H5N1 clade 2.1.3 maupun clade 2.3.2 (Gambar 2). Titer antibiodi dipengaruhi sekaligus oleh jenis vaksin dan antigen, serum ayam dan itik divaksinasi AI H5N1 memperlihatkan antibodi positif, sementara ayam kontrol (tidak divaksinasi) menunjukkan titer negatif dengan nilai probabilitas $0 \%$.

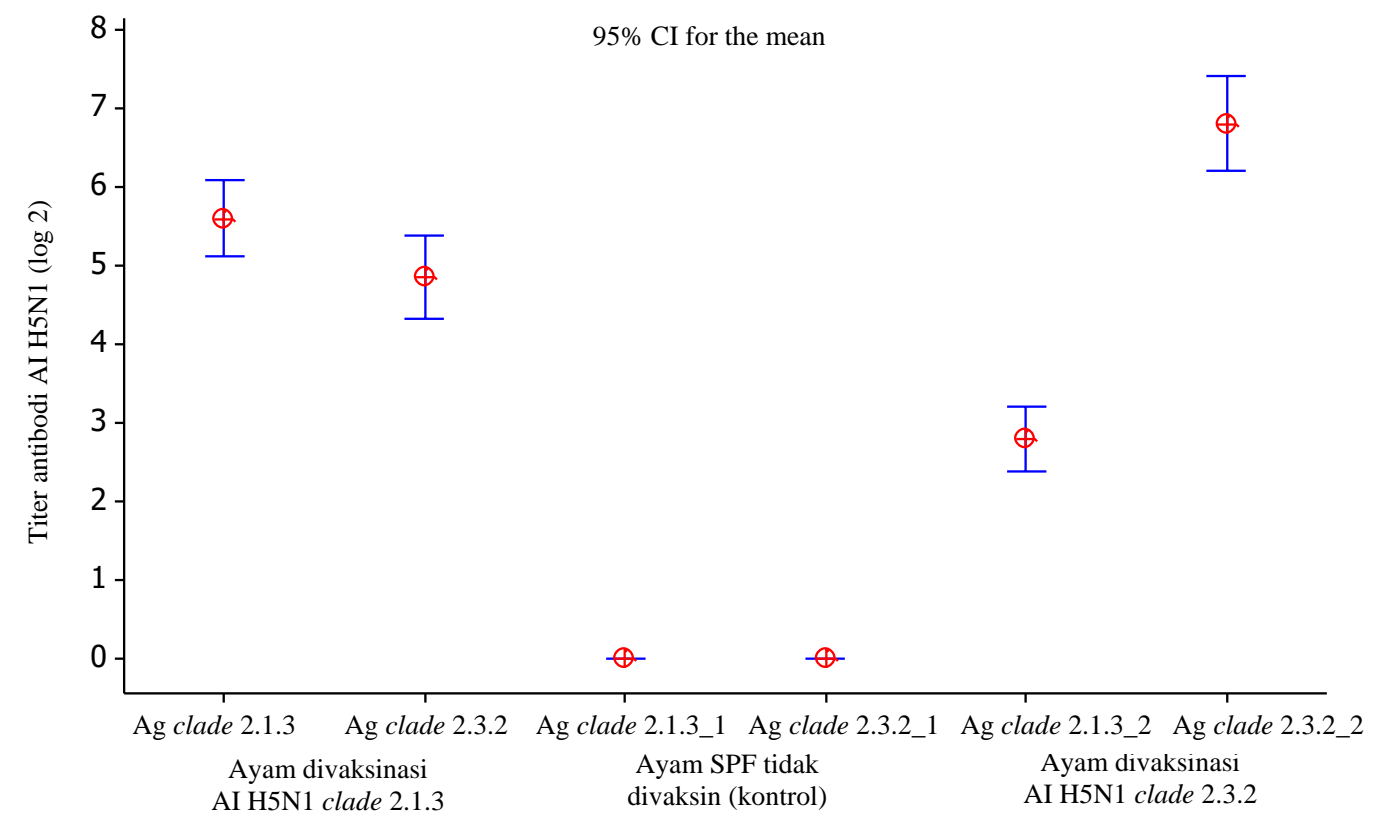

Gambar 1. Hasil uji HI reaksi silang serum ayam yang divaksinasi AI H5N1 clade 2.1.3 dan serum ayam yang divaksinasi AI H5N1 clade 2.3.2 terhadap antigen AI H5N1 calde 2.1.3 dan calde 2.3.2

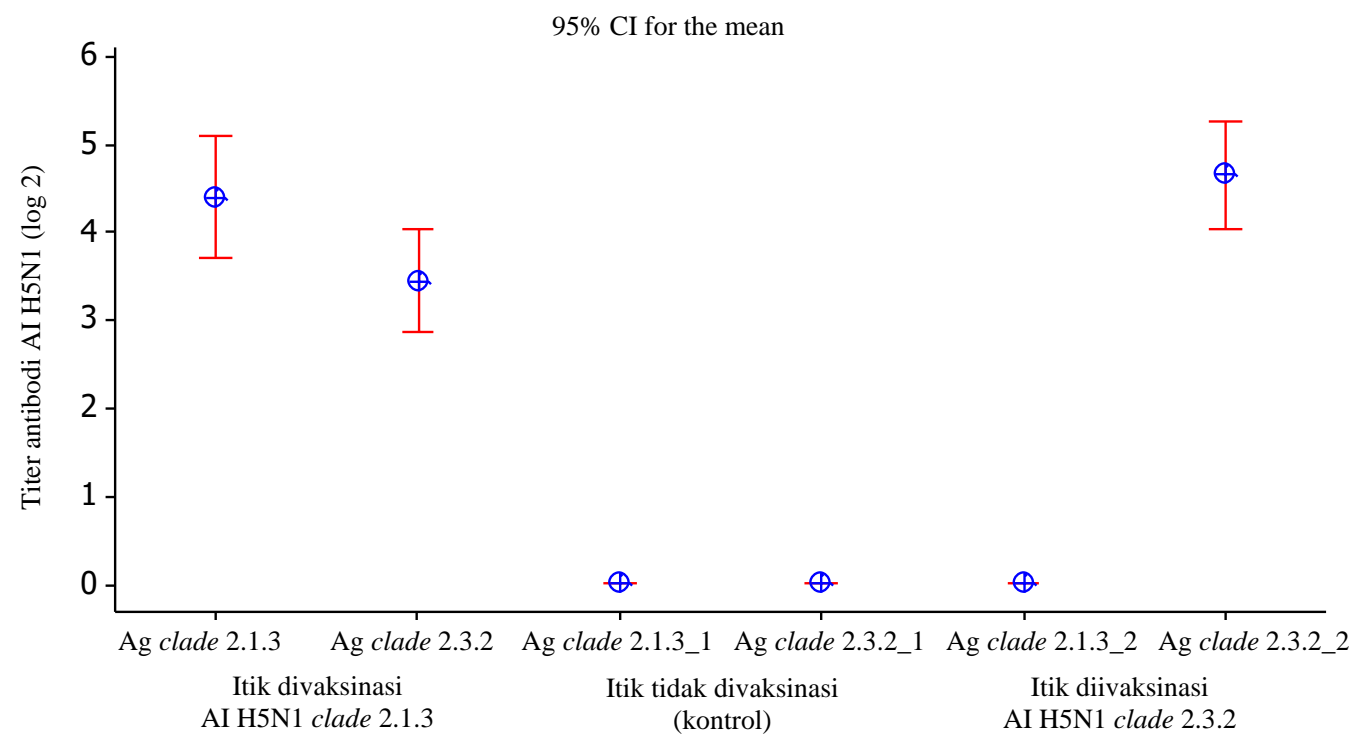

Gambar 2. Hasil uji HI reaksi silang serum itik yang divaksinasi AI H5N1 clade 2.1.3 dan serum itik yang divaksinasi AI H5N1 clade 2.3.2 terhadap antigen AI H5N1 clade 2.1.3 dan clade 2.3.2 
Hasil uji HI serum itik divaksinasi menunjukkan titer tertinggi ketika diuji dengan antigen homolog (antigen vaksin sama dengan antigen uji $\mathrm{HI}$ ). Titer antibodi reaksi silang dari uji HI memperlihatkan perbedaan yang nyata $(\mathrm{P}<0,05)$ antara serum itik divaksinasi AI H5N1 clade 2.1.3 dengan antigen uji HI clade 2.3.2 terhadap serum itik divaksinasi AI H5N1 clade 2.3.2 dengan antigen uji HI clade 2.1.3.

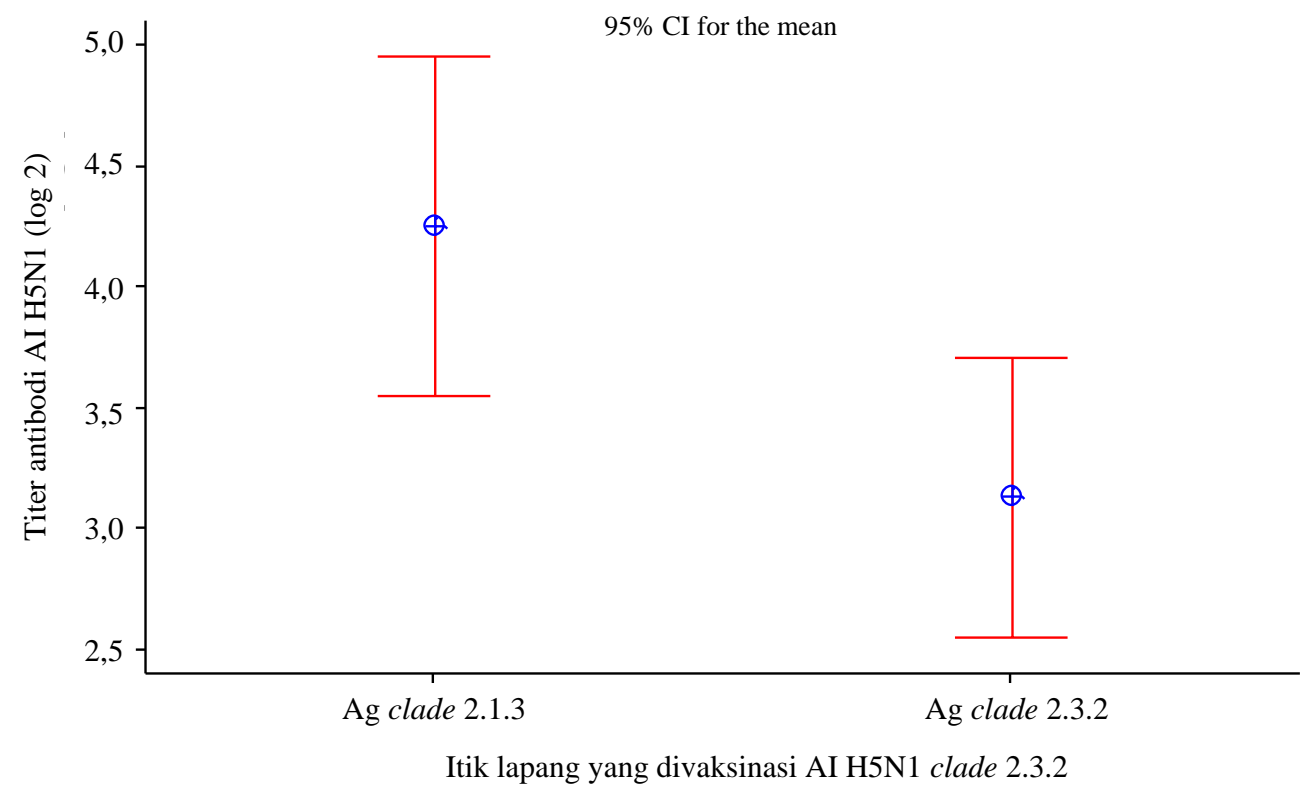

Gambar 3. Hasil uji HI reaksi silang serum itik lapang divaksinasi AI H5N1 terhadap antigen AI H5N1 clade 2.1.3 dan 2.3.2

Serum itik lapangan yaitu; serum itik pasca vaksinasi vaksin inaktif AI H5N1 terhadap antigen AI H5N1 clade 2.1.3 memperlihatkan rerata titer antibodi 4,3 log 2 dengan CI 3,55, dan reaksi silang terhadap antigen AI H5N1 clade 2.3.2 menunjukkan rerata titer antibodi 3,1 $\log 2$ dengan CI 2,5-3,7 (Gambar 3). Hasil uji HI serum itik lapangan divaksinasi AI H5N1 memperlihatkan titer antibodi tinggi dengan antigen AI H5N1 clade 2.1.3 dan reaksi silang rendah terhadap antigen AI H5N1 clade 2.3.2 (Gambar 3).

Virus avian influenza (AI) H5N1 clade 2.1.3 dan clade 2.3.2 bersifat sangat patogen. Ayam dan itik yang terinfeksi virus AI H5N1 ini, dapat menimbulkan sakit dan kematian. Pencegahan dari paparan virus H5N1 clade 2.1.3 pada ayam dan clade 2.3.2 pada itik dengan melakukan vaksinasi, agar ayam atau itik mempunyai kekebalan dengan terbentuk titer antibodi di dalam tubuh terhadap virus AI H5N1 clade 2.1.3 maupun clade 2.3.2. Titer antibodi dapat di ukur di dalam serum darah ayam maupun itik dengan uji hemaglutinasi inhibisi. Hasil studi dalam tulisan ini menunjukkan; ketika unggas (ayam atau itik) hanya divaksinasi dengan AI H5N1 clade 2.1.3 di dalam serum darah memperlihatkan reaksi silang dengan titer tinggi terhadap antigen AI H5N1 clade 2.3.2. Hal ini dapat ditunjukkan seperti yang disampaikan Indriani et al. (2014) dan Indriani \& Dharmayanti (2015), tingkat proteksi itik Mojosari yang divaksinasi dengan vaksin AI H5N1 clade 2.1.3 sebesar 80\% dan ayam SPF 90\% terhadap infeksi virus AI H5N1 clade 2.3.2 dalam kondisi laboratorium, dan titer antibodi 6log2 tidak terdeteksi adanya ekskresi virus infeksi. Studi ini juga memperlihatkan ketika unggas (ayam atau itik) divaksinasi dengan vaksin AI H5N1 clade 2.3.2, menunjukkan reaksi silang dengan titer rendah terhadap antigen AI H5N1 clade 2.1.3 yaitu; 2,8log2 dengan CI 2,4-3,2 pada ayam dan titer antibodi $0 \log 2$ pada itik, sementara titer positif menurut OIE (2013) adalah $4 \log 2$. Hasil uji reaksi silang serum ayam dan itik yang mendapat vaksinasi AI H5N1 clade 2.1.3 
lebih baik memberikan titer reaksi silang terhadap AI H5N1 clade 2.3.2, bila dibandingkan dengan serum ayam dan itik yang mendapat vaksinasi AI H5N1 clade 2.3.2 terhadap AI H5N1 clade 2.1.3. Hal ini dapat memberikan gambaran dalam pemilihan vaksin AI H5N1 guna pencegahan unggas (ayam dan itik) di lapangan. Vaksin AI H5N1 clade 2.1.3 mempunyai pola reaksi silang lebih tinggi sehingga mampu mendeteksi antigen clade 2.3.2 lebih baik sebagai uji diagnostik. Pola ini seperti ini juga pernah disampaikan oleh Ducates et al. (2011) pada studi reaksi silang clade 0, 1, 2.1, 2.2, 2.3, dan 4 AI H5N1 untuk pemilihan sebagai kandidat reagen diagnostik strain AI H5N1.

Serum itik lapangan, memperlihatkan titer HI tinggi dengan antigen AI H5N1 clade 2.1.3 dan mempunyai reaksi silang rendah terhadap antigen AI H5N1 clade 2.3.2, keadaan ini dapat menunjukkan serum uji tersebut memiliki tingkat homolog lebih dekat dengan antigen AI H5N1 clade 2.1.3 sehingga dapat diprediksi vaksin AI H5N1 yang digunakan memvaksinasi itik di lapangan adalah vaksin AI H5N1 clade 2.1.3.

\section{KESIMPULAN}

Kesimpulan menunjukkan serum ayam dan itik pasca-vaksinasi AI H5N1 clade 2.1.3 tunggal, memperlihatkan reaksi silang dengan titer HI tinggi terhadap antigen AI H5N1 clade 2.3.2, bila dibandingkan dengan serum ayam dan itik pasca vaksinasi vaksin AI $\mathrm{H} 5 \mathrm{~N} 1$ clade 2.3.2 tunggal, memperlihatkan titer $\mathrm{HI}$ rendah terhadap antigen AI H5N1 clade 2.1.3.

\section{DAFTAR PUSTAKA}

Dharmayanti, NLPI, Damayanti R, Wiyono, A, Indriani R, Darminto. 2004. Identifikasi virus avian influenza virus isolat Indonesia dengan metode Reverse Transcriptase Polymerase Chain Reaction (RT-PCR). JITV. 9:136-142.

Ducates MF, Cai Z, Peiris M, Guan Y, Ye Z, Wan XF, Webby RJ. 2011. Extent of antigenic crossreactivity among highly pathogenic H5N1 influenza viruses. J Clinic Microbiol. 49:35313536.

Gustin KM, Maines TR, Belser JA, van Hoeven N, Lu X, Sivak LDII, Chen LM, Voeten JTM, Heldens J, van den Bosch H, Ox NJ, Tumpey TM, Klimov A, Rudenko L, Donis RO, Katz1 J. 2011. Comparative immunogenicity and cross-clade protective efficacy of mammalian cellgrown inactivated and live attenuated H5N1 reassortant vaccines in ferrets. J Infect Dis. 204:1491-1499.

Indriani R, Dharmayanti NLPI, Adjid RMA. 2014. Efikasi penerapan vaksin AI H5N1 clade 2.1.3 pada itik Mojosari terhadap tantang virus AI H5N1 clade 2.3.2 pada kondisi laboratorium. JITV. 19:59-66.

Indriani R, Dharmayanti NLPI. 2014. Prototipe virus A/Duck/Sukohardjo/Bbvw-1428-9/2012 sebagai kandidat vaksin AI subtipe H5N1 clade 2.3.2 pada itik lokal. JITV. 19:152:158.

Indriani R, Dharmayanti NLPI. 2015. Tingkat perlindungan vaksin AI H5N1 clade 2.1.3 komersial terhadap virus AI H5N1 clade 2.3.2 asal itik pada ayam SPF pada kondisi laboratorium. JITV. 20:64-70.

OIE. 2012. Manual of standards for diagnostic tests and vaccines. Edisi 7. Paris (France): Office International des Epizooties. p. 436-452.

Pedersen JC. 2008. Hemagglutination-inhibition test for avian influenza virus subtype identification and the detection and quantitation of serum antibodies to the avian influenza virus. Methods Mol Biol. 2008. 436:53-66. 
Wiyono A, Indriani R, Dharmayanti NLPI, Damayanti R, Darminto. 2004. Isolasi dan karakterisasi virus highly pathogenic avian influenza subtipe H5 dari ayam asal wabah di Indonesia. JITV. 9:61-71.

Wibawa H, Priyono WB, Dharmayanti NLP, Irianingsih SH, Miswati Y, Rohmah A, Andesyha E, Romlah, Daulay RSD, Safitria K. 2012. Investigasi wabah penyakit pada itik di Jawa tengah, Yogyakarta dan Jawa Timur: Identifikasi sebuah clade baru virus avian influenza subtipe H5N1 di Indonesia. Buletin Lab Vet Balai Besar Veteriner Wates Yogyakarta. 12:4.

WHO. 2002. WHO manual on animal influenza diagnosis and surveillance [internet]. Available at: http://www.who.int/csr/resources/publications/influenza/whocdscsrncs20025rev.pdf.

\section{DISKUSI}

\section{Pertanyaan}

Apa efek silang dari AI H5N1 clade 2.1.3 dan 2.3.2. Rekomendasi vaksin AI seperti apa dengan hasil penelitian ini?

\section{Jawaban}

Efikasi vaksin AI clade 2.1.3 masih bisa memberikan perlindungan 60-80\%. Clade 2.1.3 lebih baik digunakan sebagai perangkat dignostik. 